www.jmscr.igmpublication.org

Impact Factor 5.84

Index Copernicus Value: 83.27

ISSN (e)-2347-176x ISSN (p) 2455-0450

crossref DOI: _https://dx.doi.org/10.18535/jmscr/v5i7.76

Journal Of Medical Science And Clinical Research

IGM Publication

An official Publication of IGM Publication

\title{
A Comparative Study of the Effect of Spinal And General Anaesthesia on Blood Glucose Levels in Diabetic Patients
}

\author{
Authors \\ K.Sarda Devi ${ }^{1}$, Ibemhal Heisnam ${ }^{2}$, Surmila Khoirom ${ }^{3}$, Seni Potsangbam ${ }^{4}$, \\ Rakesh Nongthombam ${ }^{5}$ \\ ${ }^{1}$ Senior Resident, Department of Anaesthesiology and Critical Care, JNIMS \\ ${ }^{2}$ Associate Professor, Department of Anaesthesiology and Critical Care, JNIMS \\ ${ }^{3,4,5}$ Assistant Professor, Department of Anaesthesiology and Critical Care, JNIMS \\ Corresponding Author \\ Dr Ibemhal Heisnam \\ Associate Professor, Department of Anaesthesiology and Critical Care \\ Jawaharlal Nehru Institute of Medical Sciences Imphal: - 795005 Manipur \\ Mobile no: 9856153557, Email: dribemhal@ gmail.com
}

\begin{abstract}
Aim of Study: Surgical stress produces metabolic as well as hormonal changes and these effects are even more pronounced in diabetics. Glycemic control is a very challenging task during surgical stress especially in diabetics. The aim of our study is to compare the effects of spinal and general anaesthesia on blood glucose level in diabetic patients.

Material and Methods: Forty diabetic patients controlled on oral hypoglycemic agent or insulin posted for elective surgical procedures were randomly divided into two groups I \& II. Group I patients were given general anaesthesia and group II received spinal anaesthesia. In both the groups, blood glucose were recorded at pre-operative period, 30 minutes intra-operative, and 60 minutes intra-operative and at 20 minutes post-operative. The results were compared and studied statistically.

Results: The mean glucose level of group I (GA) and group II (SA) were comparable at pre-operative period. The values at 30 minutes, 60 minute intra-operative and 20 minute post-operative of group I (GA) are $127.45+13.69,141.50+12.57$ and $150.30+13.18$ respectively. In group II the values are $120.50+$ 9.82 at 30 minute and $124.05+10.56$ at 60 minute intra-operative. At 20 minute post-operative it was $125.00+11.11$. When these values are compared, group I (GA) patients showed a significant increase in blood glucose level than group II (SA) patients at all the time intervals, $p(30 \mathrm{~min})=0.073, p(60 \mathrm{~min})=$ $0.000, p(20$ min post-operative $)=0.000$.

Conclusion: The increase in blood glucose level during surgical stress in diabetics is less under spinal anaesthesia than under general anaesthesia.

Key Words: Blood glucose, diabetes, spinal anaesthesia, general anaesthesia.
\end{abstract}

\section{INTRODUCTION}

The prevalence of diabetes mellitus is steadily increasing for the past 20 - 30 years. Diabetic patients are more likely to present as surgical patients with glycemic control challenges ${ }^{1}$. Hyperglycemia in peri and post-operative period increases the risk of infection, delayed wound healing and all kinds of complications thereby 
increasing post-operative morbidity and mortality in both diabetic and non-diabetic patients ${ }^{2,3}$. It has also been shown that glucose variability better predicts mortality than high mean glucose concentration. Surgical stress causes sympathetic nervous system activation, increase catabolic hormone release and pituitary gland suppression. This results in up-regulation of hepatic gluconeogenesis and glycogenolysis, decreased glucose uptake and glycogen synthesis in skeletal muscle resulting in hyperglycemia. This is more pronounced in diabetic patients as they have decreased tolerance to surgical trauma. Abolition of the catabolic hormone response to surgical stress will, therefore obtund the hyperglycemia and may be beneficial in diabetic patients ${ }^{4}$. Better glycemic control during and after surgery has been shown to improve morbidity and mortality ${ }^{5}$. Minimizing blood glucose variability during and after surgery is one component of anaesthetic care that need to be stressed. There are variations in hyperglycemic response with various anaesthetic agents and techniques ${ }^{6}$. It is important to choose an anaesthetic technique which can reduce surgical stress and consequently hyperglycemic response. Both regional and general anaesthesia have their own merit and demerits. The advantages of regional over general anaesthesia in attenuating stress response have been documented in many studies ${ }^{7}$. However, each technique has its own limitations.

The purpose of this study is to evaluate the effect of spinal and general anaesthesia on blood glucose level in diabetic patients undergoing surgery.

\section{MATERIAL AND METHODS}

After approval from institutional ethics committee, the study was conducted on forty diabetic patients controlled either on oral hypoglycemic agent or insulin, undergoing various elective surgical procedure under spinal or general anaesthesia.

Inclusion and Exclusion Criteria: Controlled diabetic patients of either sex, aged between $30-$ 60 years, ASA grade I and II scheduled for elective surgical procedure of $60-90$ minutes duration were included in the study. Uncontrolled diabetes, ASA grade III and IV patients, patient on anticoagulant and steroid therapy, pregnant women, emergency surgeries and surgeries more than 90 minutes duration were excluded from the study. Patients with $\mathrm{HbA} 1 \mathrm{c}$ level above $7 \%$ were also excluded from the study.

After taking informed consents from the patients, they were randomly divided into two groups of 20 each. Group-I patients received general anaesthesia and group-II patients were given spinal anaesthesia. All the patients were assessed pre-operatively and investigated to exclude other systemic diseases. Insulin and oral hypoglycemic agents were stopped from midnight before surgery. They were put under no insulin, no glucose protocol for assessing variations in blood sugar. Intravenous access was secured preoperatively and normal saline was used as maintenance fluid.

Group I patients were given a standard general anaesthesia regime. They were premedicated with $0.004 \mathrm{mg} / \mathrm{kg}$ glycopyrrolate and $2 \mu \mathrm{g} / \mathrm{kg}$ fentanyl, induced with $3-5 \mathrm{mg} / \mathrm{kg}$ thiopentone sodium and intubated with $0.1 \mathrm{mg} / \mathrm{kg}$ vecuronium. Maintenance was done with oxygen and nitrous oxide mixture and vecuronium. Patients were reversed with neostigmine $(0.05 \mathrm{mg} / \mathrm{kg})$ and glycopyrrolate. Group II patients received spinal anaesthesia under strict aseptic precaution. Bupivacaine $0.5 \%$ (heavy) was administered at $\mathrm{L}_{3}-\mathrm{L}_{4}$ space. A $\mathrm{T}_{4}$ segment level of analgesia was achieved. Pulse rate, blood pressure, oxygen saturation and ECG were monitored preoperatively and throughout the procedure.

Blood glucose estimation: For estimating blood glucose level, samples were collected from each patient at the following intervals using the same glucometer with different strips.

$>$ Pre-operative fasting blood glucose.

$>$ at 30 minutes after intubation in general anaesthesia group or after achieving $\mathrm{T}_{4}$ segment in spinal anaesthesia group.

$>$ at 60 minutes intra-operatively.

$>$ Post-operatively at 20 minutes after shifting the patient to post-operative ward. 
The results were compared as studied statistically.

\section{OBSERVATIONS AND RESULTS}

In this study, forty diabetic patients controlled on oral hypoglycemic agent or insulin were included into two groups Group-I (general anaesthesia group, $\mathrm{n}=20$ ) and Group-II (spinal anaesthesia group, $n=20$ ). The mean age in years in group-I (GA) was $46.25+7.31$ and in group-II (SA) was $43.05+7.85$. The mean weight is $57+6.04 \mathrm{kgs}$ and $56+5.29 \mathrm{kgs}$ respectively in group-I and II. There were no significant demographic differences between the two groups.

Table 1. : Demographic Variables of Patients

\begin{tabular}{|l|c|c|c|c|}
\hline & $\begin{array}{c}\text { Age (Yrs.) } \\
\text { Mean + SD }\end{array}$ & $\begin{array}{c}\text { Range } \\
\text { (age) }\end{array}$ & $\begin{array}{c}\text { Weight } \\
(\mathrm{kgs}) \\
\text { Mean + SD }\end{array}$ & $\begin{array}{c}\text { Range } \\
\text { (Weight) }\end{array}$ \\
\hline $\begin{array}{l}\text { Group-I } \\
\text { (G.A.) }\end{array}$ & $46.25+7.31$ & 25 & $57+6.04$ & 26 \\
\hline $\begin{array}{l}\text { Group-II } \\
\text { (S.A.) }\end{array}$ & $43.05+7.85$ & 30 & $56+5.29$ & 25 \\
\hline
\end{tabular}

The pre-operative mean blood glucose level $(\mathrm{mg} / \mathrm{dl})$ in group-I (GA) was $109.85+14.225$ while that of group-II(SA) was $112.65+9.075$ and were comparable $(\mathrm{p}=0.463)$. There was a significant rise in the blood glucose level in group-I (GA) at 30 minutes intra-operative as compared to group-II(SA), $(\mathrm{p}=0.073)$. The mean blood glucose level of group-I and II at 60 minutes were $141.50+12.57$ and $124.05+10.56$ respectively. The increase in blood glucose level between the two groups was highly significant. ( $\mathrm{p}$ $=0.000)$. The same trend continued in the postoperative also. At 20 minutes post-operative, the increase in blood glucose level in group-I (GA) as compared to group-II (SA) was also highly significant. $(\mathrm{p}=0.000)$. Table -2 shows the comparison of blood glucose level between the two groups at various time interval

Table - 2 Blood glucose level (mg/dl) at various time interval

\begin{tabular}{|c|c|c|c|c|c|c|c|c|}
\hline & Groups & $\mathrm{N}$ & Mean & $\begin{array}{c}\text { Std. } \\
\text { Deviation }\end{array}$ & $\begin{array}{l}\text { Std. Error } \\
\text { Mean }\end{array}$ & p-value* & $\begin{array}{c}\text { Mean } \\
\text { Difference }\end{array}$ & $\begin{array}{l}\text { Std. Error } \\
\text { Difference }\end{array}$ \\
\hline \multirow{2}{*}{ BEFORE OP } & I & 20 & 109.85 & 14.225 & 3.181 & \multirow[t]{2}{*}{0.463} & \multirow[t]{2}{*}{-2.800} & \multirow[t]{2}{*}{3.773} \\
\hline & II & 20 & 112.65 & 9.074 & 2.029 & & & \\
\hline \multirow{2}{*}{ IntraOp30 } & I & 20 & 127.45 & 13.690 & 3.061 & \multirow[t]{2}{*}{0.073} & \multirow[t]{2}{*}{6.950} & \multirow[t]{2}{*}{3.768} \\
\hline & II & 20 & 120.50 & 9.822 & 2.196 & & & \\
\hline \multirow{2}{*}{ IntraOp60 } & I & 20 & 141.50 & 12.572 & 2.811 & \multirow[t]{2}{*}{0.000} & \multirow[t]{2}{*}{17.450} & \multirow[t]{2}{*}{3.671} \\
\hline & II & 20 & 124.05 & 10.560 & 2.361 & & & \\
\hline \multirow{2}{*}{ PostOp20 } & I & 20 & 150.30 & 13.183 & 2.948 & \multirow[t]{2}{*}{0.000} & \multirow[t]{2}{*}{25.300} & \multirow[t]{2}{*}{3.856} \\
\hline & II & 20 & 125.00 & 11.117 & 2.486 & & & \\
\hline
\end{tabular}

*Independent t-test, GA-General Anaesthesia, SA-Spinal Anaesthesia

These result showed that there is a significant operative and post-operative period in group-I increase in blood glucose level both in the intra-

(GA) patients as compared to group-II (SA).

Table -3 .Rise in blood glucose at various time interval

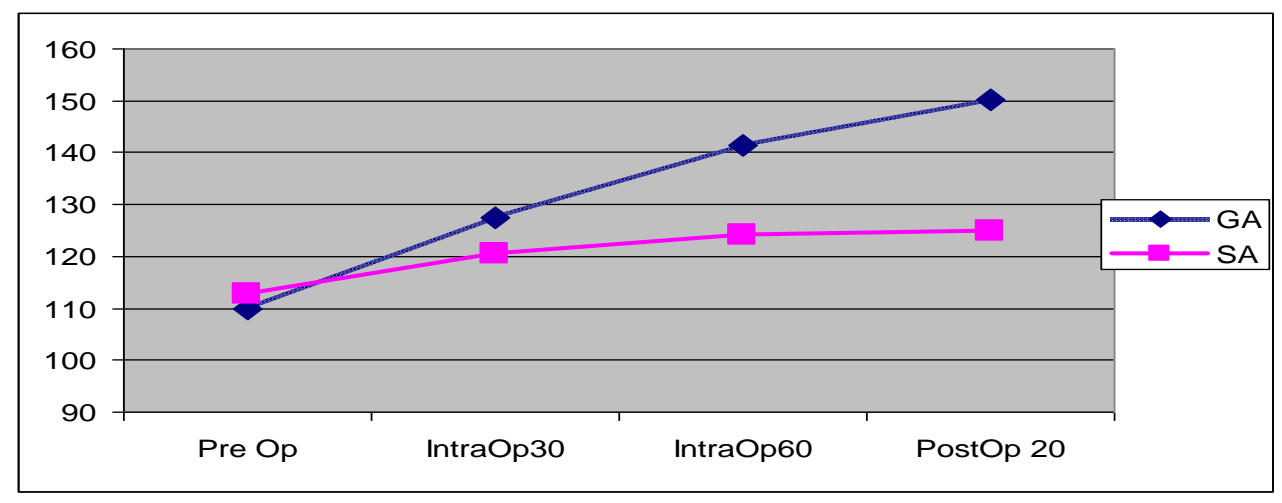


Table - 4 Comparison of mean blood glucose level at various time interval.

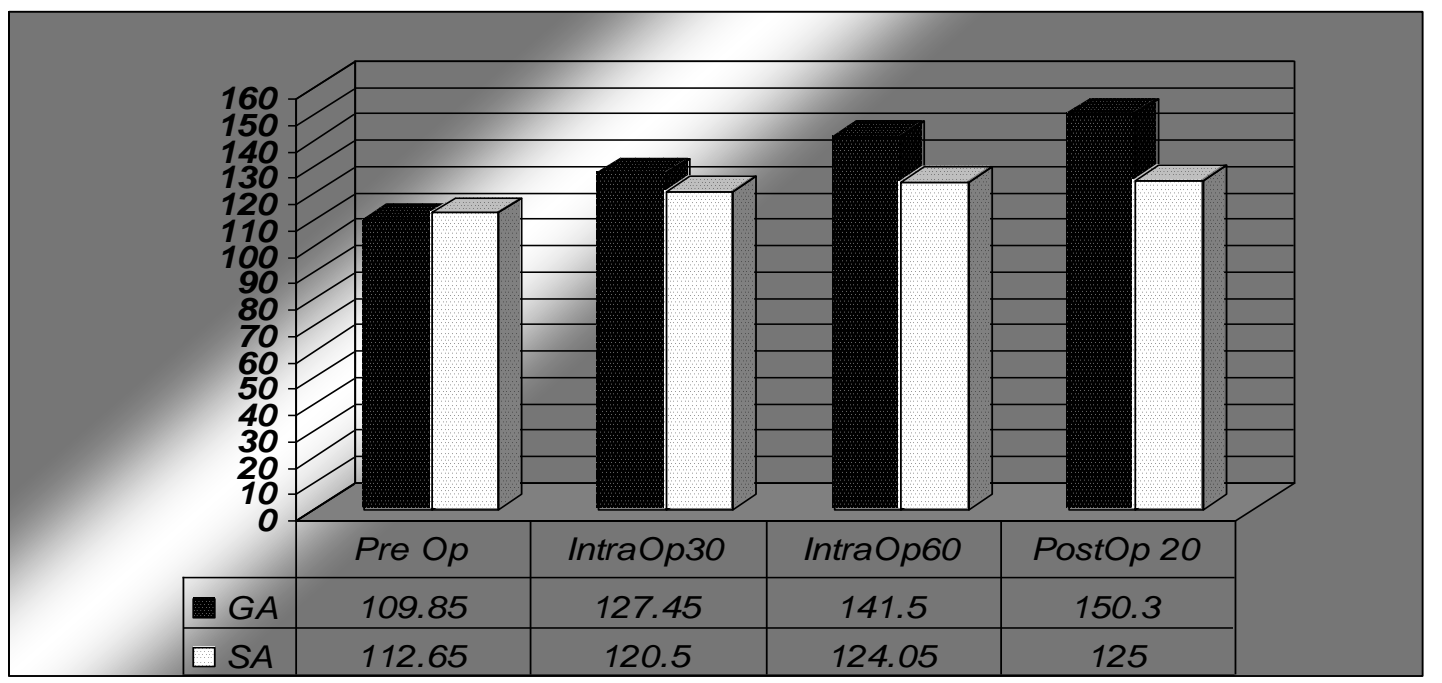

\section{DISCUSSION}

Stress response due to surgery produces a wide range of endocrinological, immunological and haematological effects in the patient. Experimental studies have shown the suppression of several aspects of immunity, such as chemotaxis, phagocytosis, and generation of free radicals and the bactericidal activity of macrophages, with an acute elevation of blood glucose level. Cortisol and catecholamine release during stress increases glucose production by increasing gluconeogenesis as well as reducing the peripheral glucose consumption. Medium and minor surgery could cause an increase of blood glucose of $1.12 \mathrm{mmol} / \mathrm{L}$ on average, as for major surgery it could be $2.05-04.48 \mathrm{mmol} / \mathrm{L}$ and for anaesthetic it could be $0.55-2.75 \mathrm{mmol} / \mathrm{L}^{8}$. All these effects are even more pronounced in diabetic patients as they have decreased tolerance to surgical trauma. As such diabetic patients are at a higher risk of stress induce hyperglycemia and its complications.

Quattara et $\mathrm{al}^{9}$ in a prospective analysis, reported that poor intra-operative blood glucose control (>200 mg/dl) was associated with greater rates of death, cardiovascular, respiratory, renal and neurological complications in diabetic patients undergoing myocardial revascularization. Duncan et $\mathrm{al}^{10}$ also reported a positive association between a blood glucose level over $200 \mathrm{mg} / \mathrm{dl}$ during cardiac surgeries and the occurrence of infection and prolonged mechanical ventilation. Surgical stress can be reduced to certain extent by different anaesthetic techniques, thereby improving the glycemic control. So, choice of anaesthesia is an important way to assure the stability of blood glucose levels during surgery. In our study, we compare the blood glucose levels of patients under spinal and general anaesthesia. The increase in blood glucose level was significantly less in spinal anaesthesia group than in general anaesthesia. Our result was similar with the work of Andre Gotts Chalk $^{11}$ which showed that spinal anaesthesia provides a smooth blood glucose control without any glucose variability in patients undergoing hip surgery. Moller et $\mathrm{al}^{12}$ in their study showed that intra and postoperative plasma cortisol and glucose levels of patients undergoing abdominal hysterectomy under spinal anaesthesia were clearly lower than general anaesthesia group. The less increase in blood glucose in spinal anaesthesia when compared to other techniques is mainly because of the complete sympathetic blockade in the region of surgery minimizing the adrenocortical activation that could occur neurogenically at the spinal cord level.

In our study the rise in blood glucose level compared with pre-operative value was more at 60 minutes in both the groups and this continued upto 20 minutes in the post-operative period. This observation somewhat correlates hyperglycemia with the severity and duration of surgery also. It 
also gives an idea when to institute insulin therapy i.e. the requirement comes when the duration of surgery is long and severity is more.

Unlike our results, Fereshtch Aimiri et $\mathrm{al}^{13}$ in their study on 50 female patients undergoing curettage surgery concluded that blood glucose and haemodynamic changes were not significantly different under spinal and general anaesthesia. Reasons may be, lower level of block required for the surgery can't completely suppress the hormonal and metabolic changes and short duration of surgery. Ramakrishna Rao et $\mathrm{al}^{14}$ concluded in their study that in a well balanced anaesthesia the degree of rise of blood glucose in controlled diabetes was not every significant when compared to non-diabetics. Stress being the main cause of hyperglycemia during and after surgery, any technique or combination of techniques which will completely or to a greater extend obtund stress response will be beneficial to surgical patients. Li Xueqiong et $\mathrm{al}^{15}$ in a meta-analysis showed that combined general - epidural anaesthesia has a better glycemic control in intra as well as post-operative period. In our study also spinal anaesthesia group provides better glycemic control over general anaesthesia group. With this finding we can minimize the intra-operative insulin requirement in diabetics by choosing a regional anaesthetic technique.

\section{CONCLUSION}

We concluded that spinal anaesthesia provides a less increase in intra-operative and post-operative blood glucose level in controlled diabetics as compared to general anaesthesia.

\section{REFERENCES}

1. Smiley DD, Umpierrez GE. Peri operative glucose control in the diabetic or nondiabetic patient. South Med J. 2006; 99(6): $580-589$.

2. Ramos M, Khalpey Z, Lipsitz S, Steinberg J. Relationship of peri operative hyperglycemia and post-operative infection in patients who undergo general and vascular surgery. Ann Surg. 2008; 248(4); 585 - 591.

3. Gandhi GY, NuttalGA, Abel MD, Mullany CJ. et al. Intra-operative hyperglycemia and perioperative outcome in cardiac surgery. Myo Clinic Proc. 2005; 80(7): $862-6$.

4. J.P. Desborough. The stress response to trauma and surgery. Br J Anaesth 2000; 85: 109 - 17.

5. Furnary AP. Gao G, Greenkemeier GL, Wu Y, Zerr KJ, Bookin SO, Floten HS, Starr A. Continuous insulin infusion reduces mortality in patients with diabetes undergoing coronary artery bypass grafting. J Thorac Cardiovasc Surg. 2003; 125(5): $1007-1021$.

6. Smetana B, Milosavljevic, Aleksandar P, Pavlovic et al. Influence of spinal and general anaesthesia on the metabolic, hormonal and haemodynamic response in elective surgical patients. Med Sci Monit 2014; 20: 1833 - 40.

7. Pan H, Yang GR. The influence of haemodynamic and glucose in elder diabetics with combined spinal and epidural analgesia.Clin Edu Gen Pract 2010; 08:524-7.

8. Liu XM. Practical Endocrinology, 1997; Beijing P: Peoples Med Press, 269.

9. Quattara A, Lecomte P, Le Manach Y, Landi $\mathrm{M}$ et al. Poor intra-operative blood glucose control is associated with a worsened hospital outcome after cardiac surgery in diabetic patients. Anaesthesiology 2005; 104(4) : 813 - 20.

10. Duncan AE, Abd - Elsayed A, Maheshwari A, Xu M, Soltesy E, Koch CG. Role of intra operative and postoperative blood glucose concentration in predicting outcomes after cardiac surgery. Anaesthesiology. 2010; 112(4) : 860 - 71 .

11. Andre Gottschalk, Birgit Rink, Smektala et al. Spinal anaesthesia protects against perioperative hyperglycemia in patients 
undergoing hip arthroplasty. J Clin Anesth 2014 Sep; 26(6): 455-60.

12. Moller IW. Hjortso E, Krantz T, Wandall E, Kehlet $H$. The modifying effect of spinal anaesthesia on intra and postoperative adrenocortical and hyperglycemic response to surgery. Acta Anaesthesiol Scand. 1984; 28(3): 266 - 9.

13. Fereshtch Amiri, Ali G Homeishi, Syed Mohammad Mehdi Aslani et al. Comparison of surgical stress responses during spinal and general anaesthesia in curettage surgery. Anesth Pain Med. 2014 August; 4(3): e 20554.

14. A. Ramakrishna Rao, $\mathrm{P}$ Indira. A comparative study of blood glucose levels under general anaesthesia in non-diabetic and controlled diabetic patients. 10SR Journal of Dental and Medical Sciences. Volume 14, Issue 10 ver 11 (Oct. 2015), PP51 - 56.

15. Li Xueqiong, Wang, Jinjing, Chen Kang et al. Effects of different types of anaesthesia on intra operative blood glucose of diabetic patients : A PRISMA - complaint systemic review and meta-analysis. Medicine. Issue: Volume 96(13), March 2017, P E 6451. 